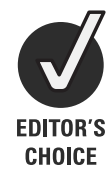

'Med. Department I,

Rheumatology, Campus

Benjamin Franklin, Charité Universitätsmedizin Berlin,

Berlin, Germany

Endokrinologikum, Berlin,

Germany

${ }^{3}$ Department of Epidemiology, German Rheumatism Research

Centre, Berlin, Germany

${ }^{4}$ Department of Rheumatology,

Dr. Horst Schmidt Kliniken,

Wiesbaden, Germany

${ }^{5}$ Department of Rheumatology, Medizinische Hochschule,

Hannover, Germany

${ }^{6}$ Rheumazentrum Ruhrgebiet,

Herne, Germany

\section{Correspondence to}

Joachim Sieper, Med.

Department I, Rheumatology,

Charité - Campus Benjamin

Franklin, Hindenburgdamm

30, 12203 Berlin, Germany;

joachim.sieper@charite.de

Received 22 December 2011 Accepted 31 January 2012

\title{
Effect of non-steroidal anti-inflammatory drugs on radiographic spinal progression in patients with axial spondyloarthritis: results from the German Spondyloarthritis Inception Cohort
}

\author{
Denis Poddubnyy, ${ }_{1}^{1}$ Martin Rudwaleit, ${ }^{2}$ Hildrun Haibel, ${ }^{1}$ Joachim Listing, ${ }^{3}$ \\ Elisabeth Märker-Hermann, ${ }^{4}$ Henning Zeidler, ${ }^{5}$ Jürgen Braun, ${ }^{6}$ Joachim Sieper ${ }^{1}$
}

\begin{abstract}
Objective To investigate the influence of non-steroidal anti-inflammatory drugs (NSAIDs) intake on radiographic spinal progression over 2 years in patients with ankylosing spondylitis (AS) and non-radiographic axial spondyloarthritis (SpA).
\end{abstract}

Methods 164 patients with axial SpA (88 with AS and 76 with non-radiographic axial SpA) were selected for this analysis based on availability of spinal radiographs at baseline and after 2 years of follow-up and the data on NSAIDs intake. Spinal radiographs were scored by two trained readers in a concealed randomly selected order according to the modified Stoke Ankylosing Spondylitis Spine Score (mSASSS) system. An index of the NSAID intake counting both dose and duration of drug intake was calculated.

Results High NSAIDs intake (NSAID index $\geq 50$ ) in AS was associated with lower likelihood of significant radiographic progression defined as an mSASSS worsening by $\geq 2$ units: $O R=0.15,95 \% \mathrm{Cl} 0.02$ to 0.96 , $p=0.045$ (adjusted for baseline structural damage, elevated $\mathrm{C}$ reactive protein (CRP) and smoking status) in comparison with patients with low NSAIDs intake (NSAID index $<50)$. This effect was most pronounced in patients with baseline syndesmophytes plus elevated CRP: mean mSASSS progression was $4.36 \pm 4.53$ in patients with low NSAIDs intake versus $0.14 \pm 1.80$ with high intake, $p=0.02$. In non-radiographic axial SpA, no significant differences regarding radiographic progression between patients with high and low NSAIDs intake were found.

Conclusion A high NSAIDs intake over 2 years is associated with retarded radiographic spinal progression in AS. In non-radiographic axial SpA this effect is less evident, probably due to a low grade of new bone formation in the spine at this stage.

Non-steroidal anti-inflammatory drugs (NSAIDs) are considered as a preferred therapy in patients with axial spondyloarthritis (SpA), including ankylosing spondylitis (AS). ${ }^{1}$ However, it has been suggested that NSAIDs might have a good symptomatic and a disease-modifying effect. It had been shown in a small retrospective study by Boersma some time ago that a continuous use of phenylbutazone was associated with retardation of spinal ossification in AS. ${ }^{2}$ In a more recent study by Wanders et al, continuous (daily) use of NSAIDs was also associated with an inhibition of radiographic progression in the spine over 2 years as compared with on-demand use. ${ }^{3}$ However, these reports have not been confirmed until now. Furthermore, NSAIDs influence on radiographic progression in early axial SpA (especially in a nonradiographic form) was not investigated so far. This analysis of the 2-year data from the German Spondyloarthritis Inception Cohort (GESPIC) was aimed at investigating the influence of NSAIDs intake on radiographic progression of the spine in patients with AS and non-radiographic axial SpA with short disease duration.

\section{METHODS}

\section{Patient selection}

Patients included in GESPIC were required to have a definite clinical diagnosis of axial SpA according to the local rheumatologist. Patients were further classified based on radiographic findings as AS or as non-radiographic axial SpA. Patients with AS ought to fulfil the modified New York criteria ${ }^{4}$ and the duration of symptoms was restricted to $\leq 10$ years at the time of inclusion. Patients with nonradiographic axial $\mathrm{SpA}$ ought to fulfil European Spondyloarthropathy Study Group criteria ${ }^{5}$ with minor modifications ${ }^{6}$ and had to have duration of symptoms of $\leq 5$ years. The baseline data of this cohort have been recently reported elsewhere. ${ }^{6}$

Radiographs of the spine (lumbar and cervical spine) and sacroiliac joints were obtained at baseline and after 2 years of follow-up. The full sets of radiographs were available for 210 GESPIC patients (115 with AS and 95 with non-radiographic axial $\mathrm{SpA}$ ) as reported elsewhere. ${ }^{7}$ Of these, information on NSAIDs intake over 2 years was available for 164 patients (88 with AS and 76 with non-radiographic axial $\mathrm{SpA}$ ) who were naïve to antitumour necrosis factor (TNF) therapy and did not receive this therapy during 2 years of follow-up.

\section{Radiographs and scoring}

X-rays of sacroiliac joints and spine (cervical and lumbar spine at baseline and after 2 years of follow-up) were performed locally. Images were centrally collected, digitised, anonymised and subsequently scored independently by two trained readers $(\mathrm{DP}, \mathrm{HH})$. The readers scored radiographs in a concealed and randomly selected order and 
Table 1 Comparative baseline characteristics of patients with non-radiographic axial SpA and AS with high (index of NSAID intake $\geq 50$ ) and low (index of NSAID intake $<50$ ) NSAIDs intake

\begin{tabular}{|c|c|c|c|}
\hline & Parameters at baseline & $\begin{array}{l}\text { Low NSAIDs intake } \\
\text { (NSAIDS index < }<0 \text { ) }\end{array}$ & $\begin{array}{l}\text { High NSAIDs intake } \\
\text { (NSAIDS index } \geq 50 \text { ) }\end{array}$ \\
\hline \multirow[t]{12}{*}{ AS $(n=88)$} & $\mathrm{n}$ & 64 & 24 \\
\hline & Age, years & $36.2 \pm 12.4$ & $38.7 \pm 9.8$ \\
\hline & Symptoms duration, years & $5.0 \pm 2.9$ & $5.5 \pm 2.7$ \\
\hline & Male sex, $\%$ & 67 & 67 \\
\hline & HLA-B27 $(+), \%$ & 86 & 79 \\
\hline & BASDAI & $3.5 \pm 2.1$ & $4.7 \pm 2.1^{*}$ \\
\hline & BASFI & $2.4 \pm 2.2$ & $4.1 \pm 2.1 \dagger$ \\
\hline & $\mathrm{CRP}, \mathrm{mg} / \mathrm{l}$ & $11.7 \pm 12.3$ & $7.9 \pm 8.7$ \\
\hline & $\mathrm{ESR}, \mathrm{mm} / \mathrm{h}$ & $21.7 \pm 19.6$ & $15.8 \pm 9.2$ \\
\hline & mSASSS, units & $5.7 \pm 11.6$ & $6.7 \pm 7.7$ \\
\hline & Syndesmophytes, $\%$ & 27 & 46 \\
\hline & Smoking, $\%$ & 39 & 38 \\
\hline \multirow[t]{12}{*}{ Non-radiographic axial $\mathrm{SpA}(\mathrm{n}=76)$} & $\mathrm{n}$ & 57 & 19 \\
\hline & Age, years & $38.6 \pm 9.3$ & $43.0 \pm 9.6$ \\
\hline & Symptoms duration, years & $3.0 \pm 2.2$ & $3.7 \pm 2.1$ \\
\hline & Male sex, $\%$ & 32 & 32 \\
\hline & HLA-B27 (+), \% & 71 & 68 \\
\hline & BASDAI & $3.8 \pm 1.8$ & $5.0 \pm 1.9 *$ \\
\hline & BASFI & $2.4 \pm 1.9$ & $3.9 \pm 2.4^{*}$ \\
\hline & CRP, mg/l & $6.2 \pm 14.4$ & $6.2 \pm 7.0$ \\
\hline & $\mathrm{ESR}, \mathrm{mm} / \mathrm{h}$ & $12.1 \pm 9.1$ & $13.4 \pm 8.8$ \\
\hline & mSASSS, units & $2.6 \pm 4.8$ & $1.6 \pm 4.0$ \\
\hline & Syndesmophytes, $\%$ & 14 & 11 \\
\hline & Smoking, \% & 32 & 26 \\
\hline
\end{tabular}

${ }^{*} \mathrm{p}<0.05 ; \dagger p<0.01$ for the difference between two groups.

AS, ankylosing spondylitis; BASDAl, the Bath Ankylosing Spondylitis Disease Activity Index; BASFl, the Bath Ankylosing Spondylitis Functional Index; CRP, C reactive protein; ESR, erythrocyte sedimentation rate; HLA, human leucocyte antigen; mSASSS, modified Stoke Ankylosing Spondylitis Spine Score; NSAID, non-steroidal anti-inflammatory drug; SpA, spondyloarthritis.

were blinded for all clinical data. Grading of sacroiliitis was performed according to the established scoring system. ${ }^{4}$ Spinal radiographs were scored according to the modified Stoke Ankylosing Spondylitis Spine Score (mSASSS) scoring system. ${ }^{8}$ In addition to lateral views, anteroposterior views of the lumbar spine (left and right corners of the vertebral bodies from Th12 to S1) were scored for the presence of syndesmophytes.

\section{NSAIDs intake}

Data on NSAIDs intake (dose and frequency of intake) were collected at baseline and every 6 months thereafter during 2 years of follow-up. An index of the NSAID intake, ${ }^{9}$ as recommended by ASAS (Assessment of SpondyloArthritis international Society), accounting for both dose and duration/regiment of drug intake (0: no NSAIDs intake at all, 100: daily NSAIDs intake in a dose equivalent to diclofenac $150 \mathrm{mg}$ over the whole period of interest) was calculated. High NSAIDs intake was defined as a mean NSAIDs intake index over 2 years of $\geq 50$, and low NSAIDs intake as a mean NSAIDs intake index $<50$.

\section{Statistics}

Status scores for baseline and follow-up were calculated by taking the mean of the scores of both readers. Radiographic progression was calculated by the difference between follow-up and baseline mean values. Agreement between readers was estimated by the intraclass correlation coefficient (ICC). Significant radiographic progression was defined as a worsening of the mSASSS score by $\geq 2$ units over 2 years. ${ }^{8} 10$ Syndesmophytes were considered to be absent or present if both readers agreed on it.

$\mathrm{X}^{2}$ test, Mann-Whitney $\mathrm{U}$ test and one-way analysis of variance were applied as appropriate. Non-parametric analysis of covariance $^{11}$ was used to compare changes in mSASSS between groups after adjustment for mSASSS status at baseline. A multivariate logistic regression analysis was performed in order to analyse the influence of NSAIDs intake on radiographic spinal progression with adjustment for other factors. A $p$ value of $<0.05$ was considered to be statistically significant.

\section{Ethical approval}

The study protocol was approved by the central ethical committee of the coordinating centre (Charité Universitätsmedizin Berlin, Berlin, Germany) and by all local ethical committees of the participating centres. Written informed consent was obtained from all patients.

\section{RESULTS}

The mean NSAID intake index over 2 years was $33.7 \pm 28.0$ (range 0-100) in the AS and 32.2 26.7 (range 0-100) in the non-radiographic axial SpA group. Overall, 24 with AS (27.3\%) and 19 patients with non-radiographic axial SpA $(25.0 \%)$ had a high NSAIDs (NSAID intake index $\geq 50$ ) intake during 2 years of follow-up. Comparative characteristics of patients with low and high NSAIDs intake are presented in table 1. As shown in the table, patients with a high NSAIDs intake had at baseline higher clinical disease activity (as measured by the Bath Ankylosing Spondylitis Disease Activity Index) and higher level of functional impairment (as measured by the Bath Ankylosing Spondylitis Functional Index) as compared with patients with low NSAIDs intake. Patients with AS and high NSAIDs intake had also numerically higher frequency of syndesmophytes at baseline and higher baseline mSASSS score. Other parameters were similar in the subgroups. Selective inhibitors of cyclo-oxygenase-2 (COX-2 inhibitors: celecoxib, etoricoxib, rofecoxib, 

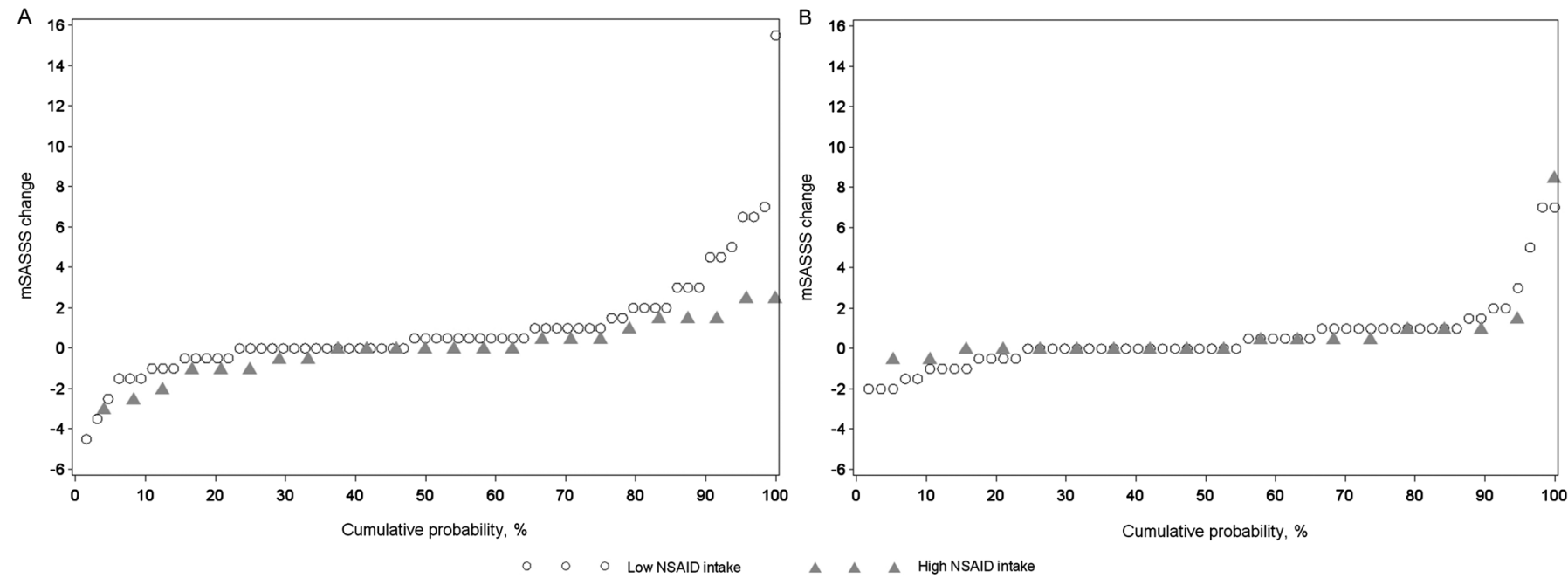

Figure 1 Cumulative probability plot of the mSASSS progression in patients with AS (A) and non-radiographic axial SpA (B) over 2 years in relation to the NSAID intake. Low NSAID intake: NSAID intake index < 50; high NSAID intake: NSAID intake index $\geq 50$. AS, ankylosing spondylitis; mSASSS, modified Stoke Ankylosing Spondylitis Spine Score; NSAID, non-steroidal anti-inflammatory drug; SpA, spondyloarthritis.
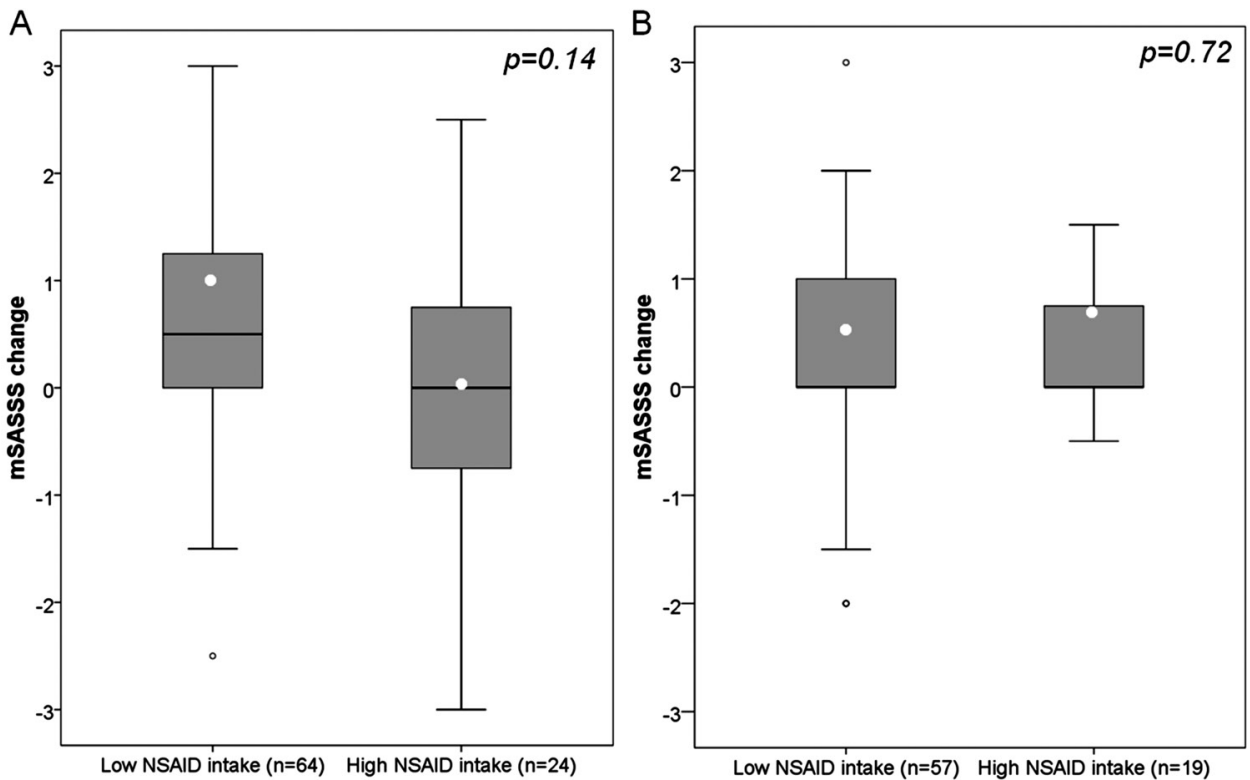

Figure 2 Radiographic spinal progression (change of the mSASSS score) over 2 years in relation to NSAID intake in patients with AS (A) and nonradiographic axial $\mathrm{SpA}(\mathrm{B})$. Each box indicates the median value, the first and the third quartiles; whiskers demonstrate minimal and maximal values, white dots inside the boxes - mean values, outside circles - outliers. Low NSAID intake: NSAID intake index <50; high NSAID intake: NSAID intake index $\geq 50$. AS, ankylosing spondylitis; mSASSS, modified Stoke Ankylosing Spondylitis Spine Score; NSAID, non-steroidal anti-inflammatory drug; $\mathrm{SpA}$, spondyloarthritis.

valdecoxib), as opposed to non-selective COX inhibitors, were used in similar proportions of patients with high and low NSAIDs intake: $29.2 \%$ and $32.1 \%$, respectively, in AS; $42.1 \%$ and $33.3 \%$, respectively, in non-radiographic axial SpA. Among non-selective COX inhibitors, diclofenac, ibuprofen, indometacin and piroxicam were used most frequently and accounted for more than $50 \%$ of all NSAIDs used.

There was a very good agreement between the two readers regarding status scores (mSASSS) of spinal radiographic damage: the ICC was 0.92 (95\% CI 0.90 to 0.94 ) at baseline and 0.92 (95\% CI 0.89 to 0.94$)$ at year 2 . The agreement regarding the mSASSS change score was moderate with an ICC coefficient of $0.33(95 \%$ CI 0.19 to 0.49$)$.
The cumulative probability plot presented in figure 1A demonstrates the divergence of mSASSS change on the patient level with less radiographic progression in the group of AS patients with high NSAIDs intake. The mean mSASSS change over 2 years in AS was $0.02 \pm 1.39$ in patients with high NSAIDs intake versus $0.96 \pm 2.78$ in the subgroup with low NSAIDs intake, respectively; $\mathrm{p}=0.142$ (after adjustment for radiographic status at baseline $\mathrm{p}=0.22$ ) (figure $2 \mathrm{~A}$ ). The trend for reduced radiographic spinal progression in patients with high NSAIDs intake was also present if other thresholds for the index of NSAIDs intake were chosen (eg, tertiles). In AS patients with an NSAID intake index values of $<33,33-65$ and $\geq 66$, the mSASSS changes over 2 years were $0.86 \pm 2.93,0.75 \pm 1.84$ and $0.10 \pm 1.70$ units, respectively 
Table 2 Association of NSAIDs intake with radiographic spinal progression (mSASSS change $\geq 2$ over 2 years) in patients with AS and non-radiographic axial SpA in the multivariate logistic regression analysis

\begin{tabular}{|c|c|c|c|c|}
\hline \multirow[b]{2}{*}{ Parameters } & \multicolumn{2}{|l|}{ AS $(n=88)$} & \multicolumn{2}{|c|}{ Non-radiographic axial $\mathrm{SpA}(\mathrm{n}=76$} \\
\hline & OR $(95 \%$ Cl) & p Value & OR (95\% Cl) & p Value \\
\hline NSAID intake index over 2 years, $>50$ vs $\leq 50$ & $0.15(0.02$ to 0.96$)$ & 0.045 & 0.60 (0.06 to 6.61$)$ & 0.679 \\
\hline Syndesmophytes at baseline, present vs not present & 6.80 (1.78 to 25.95$)$ & 0.005 & 15.4 (2.59 to 91.7$)$ & 0.003 \\
\hline CRP at baseline, $>6$ vs $\leq 6 \mathrm{mg} / \mathrm{l}$ & $1.34(0.37$ to 4.93$)$ & 0.656 & 0.37 (0.03 to 4.36$)$ & 0.432 \\
\hline \multirow[t]{2}{*}{ Smoking status at baseline, present vs not present } & 3.45 (0.97 to 12.23$)$ & 0.055 & $1.01(0.14$ to 7.26$)$ & 0.989 \\
\hline & $R$-square $=0.289$ & & $R$-square $=0.268$ & \\
\hline
\end{tabular}

AS, ankylosing spondylitis; CRP, C reactive protein; mSASSS, modified Stoke Ankylosing Spondylitis Spine Score; NSAID, non-steroidal anti-inflammatory drug; SpA, spondyloarthritis.

( $p=0.587$ for the comparison of all three groups). However, the analysis with continuous variables (mean NSAIDs index over 2 years and mSASSS change score) demonstrated only a weak and statistically non-significant negative correlation ( $r=-0.026)$.

Similarly, less AS patients in the group with high NSAIDs intake showed radiographic spinal progression defined as a worsening of the mSASSS score by 2 units and more over 2 years in comparison with the patients with low NSAIDs intake: $8.3 \%$ $(\mathrm{n}=2)$ versus $21.9 \%(\mathrm{n}=14)$, respectively, $\mathrm{p}=0.142$; unadjusted $\mathrm{OR}=0.33$ (95\% CI 0.07 to 1.55$), \mathrm{p}=0.159$. After adjustment of the OR for factors shown to be independently associated with radiographic spinal progression (mSASSS worsening by $\geq 2$ units) in GESPIC previously (presence of radiographic damage at baseline, elevated acute phase reactants (C reactive protein (CRP)), smoking), ${ }^{12}$ the association of retarded radiographic spinal progression with high NSAIDs intake became significant: $\mathrm{OR}=0.15$ ( $95 \%$ CI 0.02 to 0.96 ), $\mathrm{p}=0.045$ (table 2 ). Similar results were obtained after adjustment for the elevated (>20 mm/h) erythrocyte sedimentation rate at baseline instead of CRP: OR for an association of the spinal progression with NSAIDs intake $=0.15$ (95\% CI 0.02 to 0.94$), \mathrm{p}=0.042$.

The positive effect of the NSAIDs intake was mostly evident in patients who were at high risk for radiographic progression due to the presence of syndesmophytes and elevated acute phase reactants. mSASSS progression over 2 years in AS patients with normal $(\leq 6 \mathrm{mg} / \mathrm{l})$ time-averaged CRP over 2 years was $0.23 \pm 1.58$ and $0.05 \pm 1.41$ in the groups with low $(n=32)$ and high $(n=11)$ NSAIDs intake, respectively $(\mathrm{p}=0.54)$. In contrast, in AS patients with elevated time-averaged CRP ( $>6 \mathrm{mg} / \mathrm{l})$, the mSASSS progression was $1.69 \pm 3.48$ versus $0.0 \pm 1.41$ in patients with low $(n=32)$ and high $(n=13)$ NSAIDs intake, respectively $(p=0.11)$. Similarly, in AS patients without syndesmophytes at baseline mSASSS progression was $0.32 \pm 1.31$ versus $-0.04 \pm 0.97$ with low $(n=47)$ and high $(n=13)$ NSAIDs intake, respectively $(p=0.32)$, while in patients with syndesmophytes at baseline the progression was $2.74 \pm 4.58(\mathrm{n}=17)$ versus $0.09 \pm 1.80(\mathrm{n}=11)$, respectively; $\mathrm{p}=0.076$. The difference was even clearer (and statistically significant) in patients with both syndesmophytes and elevated time-averaged CRP: $4.36 \pm 4.53$ versus $0.14 \pm 1.80$ in patients with low and high NSAIDs intake, respectively $(p=0.02)$ (figure $3 \mathrm{~A}$ ), while there was nearly no progression in patients without both risk factors $(0.35 \pm 1.07$ vs $0.07 \pm 1.06$, respectively; $p=0.48)$ (figure $3 \mathrm{~B}$ ) or if only one risk factor was present: $0.17 \pm 1.95$ versus $-0.10 \pm 1.39$ in patients with low $(n=27)$ and high $(n=10)$ NSAIDs intake, respectively $(p=0.60)$.

There was also a statistically non-significant trend towards lower frequency of new syndesmophytes in AS patients with high NSAIDs intake in comparison with the group with low NSAIDs intake: $12.5 \%(n=3)$ versus $15.6 \%(n=10)$, respectively.
No clear association was found between radiographic spinal progression and NSAIDs intake if the NSAID dose only or duration of the NSAID intake only were taken into account (data not shown). COX selectivity was not identified as a factor influencing radiographic progression (data not shown). No differences in the proportion of patients who underwent physiotherapy could be found while comparing high and low NSAIDs users, as well as patients with and without radiographic progression (data not shown).

There was no clear and consistent difference between low and high NSAIDs intake patients in non-radiographic axial SpA: observed mSASSS change score was $0.51 \pm 1.72$ versus $0.74 \pm 1.95$ in patients with low and high NSAIDs intake, respectively; $p=0.72$ (after adjustment for radiographic status at baseline $\mathrm{p}=0.58$ ) (figure $2 \mathrm{~B}$ ). Similar results were seen with the NSAID index values of $<33,33-65$ and $\geq 66$ : mSASSS change was $0.60 \pm 1.70,0.59 \pm 2.26$ and $0.41 \pm 0.58$, respectively; $p=0.952$. Only $5.3 \%(n=1)$ of the patients with high NSAIDs intake and $10.5 \%$ ( $n=6$ ) with low NSAIDs intake showed an mSASSS worsening by $\geq 2$ units over 2 years, $p=0.492$; $O R=0.47(95 \%$ CI 0.05 to 4.20 ), $p=0.501$. After adjustment for baseline radiographic damage, elevated acute phase reactants and smoking, this association remained statistically non-significant: $\mathrm{OR}=0.60$ (95\% CI 0.06 to 6.61), p=0.679 (table 2). New syndesmophytes occurred in $5.3 \%(n=1)$ versus $3.5 \%(n=2)$ of the patients with high and low NSAIDs intake, respectively.

Regarding progression of radiographic sacroiliitis the following results were obtained: in the AS group 0 patients with high NSAID intake and $14.1 \%(n=9)$ with low NSAIDs intake showed progression of sacroiliitis by at least one grade over 2 years in the opinion of both readers $(p=0.053)$. In the non-radiographic axial SpA group, 15.8\% $(n=3)$ of the patients with high NSAIDs intake and $17.5 \%(\mathrm{n}=10)$ demonstrated such a progression $(p=0.86)$.

\section{DISCUSSION}

In the current study, we present data showing that NSAIDs retard radiographic spinal progression as assessed by an mSASSS change over 2 years in patients with AS confirming, therefore, earlier data. ${ }^{2}$ Although the clear difference in the absolute mSASSS change between subgroups with high and low NSAIDs intake was statistically non-significant (probably due to a relatively low sample size and high variation of the radiographic progression), an analysis of significant radiographic progression (ie, mSASSS worsening in 2 units and more over 2 years) adjusted for factors predictive for radiographic spinal progression, ${ }^{12}$ especially for the presence of structural damage at baseline, revealed a significant association between high NSAIDs intake and low radiographic progression in AS (OR=0.15, 95\% 
A AS patients with syndesmophytes at baseline and elevated time-averaged CRP

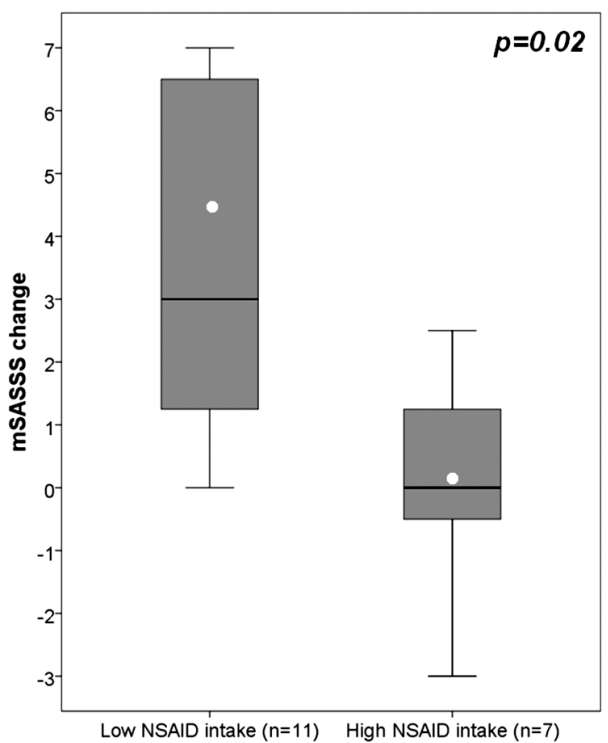

B AS patients without syndesmophytes and with normal time-averaged CRP

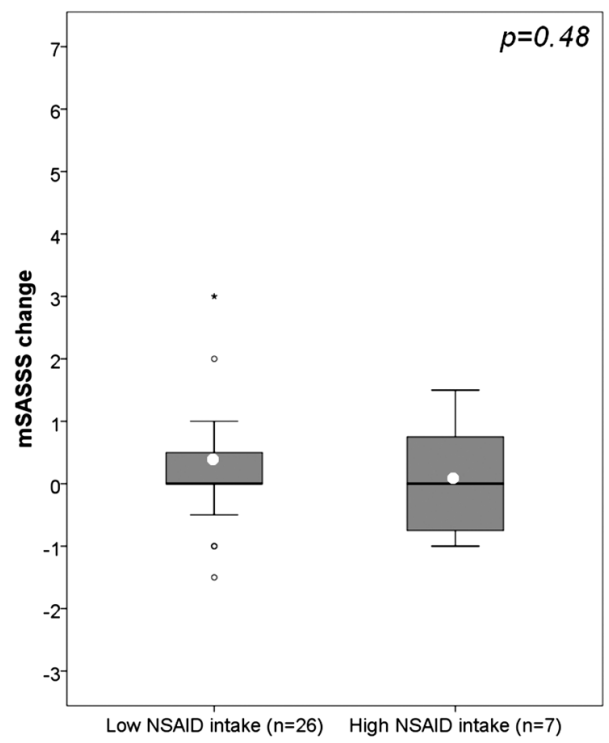

Figure 3 Radiographic spinal progression (change of the mSASSS score) over 2 years in relation to NSAID intake in AS patients with presence (A) and absence (B) of risk factors for progression (syndesmophytes at baseline and elevated time-averaged CRP). Each box indicates the median value, the first and the third quartiles; whiskers demonstrate minimal and maximal values, white dots inside the boxes - mean values, outside circles and asterisk - outliers. Low NSAID intake: NSAID intake index <50; high NSAID intake: NSAID intake index $\geq 50$. Time-averaged CRP: CRP levels were determined at baseline and every 6 months thereafter during 2 years of follow-up. AS, ankylosing spondylitis; CRP, C reactive protein; mSASSS, modified Stoke Ankylosing Spondylitis Spine Score; NSAID, non-steroidal anti-inflammatory drug.

CI 0.02 to $0.96, \mathrm{p}=0.045$ : table 2). Adjustment for baseline factors such as baseline damage, smoking and CRP was important because there was heterogenity among the groups at baseline and because these factors have been shown to be predictors of progression. It was remarkable to see a retarding effect of NSAIDs particularly in the group of AS patients with high NSAID intake because these patients had a higher proportion of syndesmophytes (table 1) - the strongest predictor of progression as compared with smoking and CRP - and, therefore, were more likely to progress compared with patients with low intake of NSAIDs who had less frequently syndesmophytes.

In AS patients with normal CRP and/or no syndesmophytes at baseline there was nearly no radiographic progression independently from the NSAIDs intake. In contrast, the effect of high NSAIDs intake was most pronounced in patients with both syndesmophytes at baseline and elevated CRP, suggesting that the observed NSAID effect on radiographic progression is mostly driven by this subgroup, which constitutes $25 \%$ of the whole AS group in the current study. These data indicate that continuous NSAIDs intake might especially be of benefit in these patients.

In non-radiographic axial SpA, however, this effect could not be shown which is most likely related to a relatively low radiographic spinal progression rate in this subgroup in general and nearly no new bone formation (syndesmophytes) in particular. Furthermore, in this group the mSASSS might be more driven by erosive changes than by new bone formation.

Interestingly, there was also a trend towards reduced radiographic sacroiliitis progression in patients with AS and high NSAIDs intake, but this was not the case in non-radiographic axial SpA. We speculate that this could be related to the interference of the NSAIDs with the new bone formation, which is mostly responsible for radiographic progression in advanced sacroiliitis, as opposed to the destructive/erosive change at the early disease.
In this analysis we used the recently introduced index of NSAIDs intake. ${ }^{9}$ This index accounts for dose and duration of NSAIDs intake which seem to be both relevant for retardation of radiographic spinal progression, since no clear differences in radiographic progression could be found if dose or duration of intake only were taken into account. The analysis with continuous variables (mean NSAIDs index over 2 years and mSASSS change score) demonstrated only a weak and statistically nonsignificant negative correlation between NSAIDs index and radiographic progression indicating a non-linear character of the relationship. Therefore, a clinically relevant threshold (NSAIDs intake index of 50) was chosen for this analysis to differentiate between low and high NSAID intake. Other thresholds (eg, tertiles) provided comparable results with the clearest effect of NSAIDs seen in the highest tertile, but the resulting patient numbers per group were too small to show significant differences.

Earlier investigations indeed already indicated that NSAIDs might have an inhibitory effect on new bone formation. There are several observational studies indicating a retardation of fracture healing ${ }^{13-16}$ or loosening of the hip endoprosthesis ${ }^{17}$ related to NSAIDs use. Furthermore, NSAIDs have been used for the prevention of heterotopic ossification after orthopaedic surgery, for example, total hip arthroplasty, ${ }^{18-25}$ hip resurfacing ${ }^{26}$ or fractures (eg, acetabular fractures). ${ }^{27} 28$

The observed inhibition of new bone formation by NSAIDs can probably best be explained by the inhibition of prostaglandins (especially prostaglandin $\mathrm{E}_{2}$ ) synthesis mediated by COX2. ${ }^{29}$ Prostaglandin $\mathrm{E}_{2}$ is able to stimulate new bone formation by increasing the replication and differentiation of osteoblasts. ${ }^{30}$ Prostaglandins also support blood supply to the site of new bone formation by causing vasodilatation and by promoting angiogenesis. $^{31}{ }^{32}$ In experiments with COX-2 knockout mice, healing of the stabilised tibia fracture was delayed in comparison with wildtype animals and to COX-1 knockouts. ${ }^{33}$ Similarly, NSAIDs were able to retard a bone morphogenetic protein 7 induced ectopic 
bone formation in an experimental mouse model indicating an important role of COX-mediated prostaglandin synthesis in new bone formation. ${ }^{34}$ Since retardation of the new bone formation is related to COX-2 inhibition, no substantial differences are expected between different NSAIDs, because in therapeutic concentrations all NSAIDs, independently from their COX-selectivity, inhibit COX-2 to nearly the same extent. ${ }^{35}$

NSAIDs are considered as a preferred therapy in patients with axial SpA due to their high symptomatic activity. ${ }^{1}$ In addition, a small but significant decrease of CRP has been seen in AS patients treated with NSAIDs. ${ }^{36} 37$ If the structure-modifying effect of NSAIDs in AS is confirmed, it would be an additional argument to administer NSAIDs more, especially in patients with clinical indications for NSAIDs and in patients who are at risk for radiographic spinal progression such as presence of syndesmophytes and/or an elevated level of acute phase reactants. The potential cardiovascular, gastrointestinal and other side effects of continuous NSAIDs intake have been investigated in the greatest detail and we have argued recently that the benefit of such a treatment normally outweighs the risk in AS. ${ }^{38}$ The data presented here add further evidence to this.

Due to the character of our study there are some limitations which might have influenced the final results. GESPIC is an observational cohort and includes therefore a relative heterogeneous (in comparison with 'standard' drug investigating clinical trials) patient population, which was included based on diagnosis and symptom duration without further limitations. On the other hand, this comes closer to daily clinical practise. GESPIC was not specially designed and powered for the investigation of the influence of NSAIDs on radiographic progression. The NSAIDs doses and duration of intake were not strictly counted, but relied on the information given by the patient every 6 months, and represent therefore the best possible approximation. Finally, the treatment with NSAIDs was heterogeneous with a variety of NSAIDs used, but again this is closer to daily clinical practise.

In conclusion, we add further evidence here that NSAIDs seem to retard new bone formation in AS patients. Given the good anti-inflammatory capacity of TNF blockers in AS but their failure in stopping new bone formation, a trial combining TNF blocker and NSAIDs treatment would especially be of interest addressing the question whether new bone formation can be inhibited, in addition to suppressing inflammation and improving signs and symptoms.

Contributors All the authors fulfil the authorship criteria. Contributors not fulfilling the authorship criteria are listed in the acknowledgement part.

Acknowledgements The authors thank M Leirisalo-Repo, Finland, D van der Heijde, The Netherlands and M Dougados, France, for scientific advice on the design of the cohort. The authors are grateful to Beate Buss and Petra Tietz for monitoring the cohort, Johanna Callhoff, Anja Weiss and Martina Niewerth for the data management support, Janis Vahldiek and Georg Heine for the x-ray images handling and for the development of the image scoring interface, and to all patients who voluntarily participate in this cohort. The authors further like to thank the following rheumatologists for inclusion of their patients: H Brandt, J Brandt, G-R Burmester, H Deister, E Edelmann, J Emmerich, M Enderlein, A Gauliard, E Gromnica-lhle, F Heldmann, S Hermann, U von Hinüber, Ü Hübner, K Karberg, C Kedor, H Nüßlein, R Pelle-Lohfink, D Pick, G Reichmuth, M Rihl, S Schnarr, U Schneider, I-H Song, I Spiller, U Syrbe, V Walz, S Wassenberg, H M Wisseler and S Zinke.

Funding As part of the German competence network in rheumatology (Kompetenznetz Rheuma), GESPIC has been financially supported by the German Federal Ministry of Education and Research (Bundesministerium für Bildung und Forschung - BMBF), grant number: FKZ 01G19946. As funding by BMBF was reduced according to schedule in 2005 and stopped in 2007, complementary financial support has been obtained also from Abbott, Amgen, Centocor, Schering-Plough and Wyeth. Since 2010, additional support has being obtained also from ANCYLOSS and ArthroMark projects funded by the German Federal Ministry of Education and Research.

\section{Competing interests None.}

Ethics approval Approval provided by the Central Ethics Committee (Berlin) und local committees of the involved centres.

Provenance and peer review Not commissioned; externally peer reviewed.

\section{REFERENCES}

1. Braun J, van den Berg R, Baraliakos X, et al. 2010 update of the ASAS/EULAR recommendations for the management of ankylosing spondylitis. Ann Rheum Dis 2011;70:896-904.

2. Boersma JW. Retardation of ossification of the lumbar vertebral column in ankylosing spondylitis by means of phenylbutazone. Scand J Rheumatol 1976;5:60-4.

3. Wanders A, Heijde D, Landewé R, et al. Nonsteroidal antiinflammatory drugs reduce radiographic progression in patients with ankylosing spondylitis: a randomized clinica trial. Arthritis Rheum 2005;52:1756-65.

4. van der Linden S, Valkenburg HA, Cats A. Evaluation of diagnostic criteria for ankylosing spondylitis. A proposal for modification of the New York criteria. Arthritis Rheum 1984:27:361-8.

5. Dougados M, van der Linden S, Juhlin R, et al. The European Spondylarthropathy Study Group preliminary criteria for the classification of spondylarthropathy. Arthritis Rheum 1991;34:1218-27.

6. Rudwaleit M, Haibel H, Baraliakos X, et al. The early disease stage in axial spondylarthritis: results from the German Spondyloarthritis Inception Cohort. Arthritis Rheum 2009;60:717-27.

7. Poddubnyy D, Rudwaleit M, Haibel H, et al. Rates and predictors of radiographic sacroiliitis progression over 2 years in patients with axial spondyloarthritis. Ann Rheum Dis 2011;70:1369-74.

8. Creemers MC, Franssen MJ, van't Hof MA, et al. Assessment of outcome in ankylosing spondylitis: an extended radiographic scoring system. Ann Rheum Dis 2005;64:127-9.

9. Dougados M, Simon P, Braun J, et al. ASAS recommendations for collecting, analysing and reporting NSAID intake in clinical trials/epidemiological studies in axial spondyloarthritis. Ann Rheum Dis 2011;70:249-51.

10. Baraliakos X, Listing J, Rudwaleit M, et al. Radiographic progression in patients with ankylosing spondylitis after 2 years of treatment with the tumour necrosis factor alpha antibody infliximab. Ann Rheum Dis 2005;64:1462-6.

11. Bathke A, Brunner E. A nonparametric alternative to analysis of covariance. In: Akritas MG, Politis DN, eds. Recent Advances and Trends in Nonparametric Statistics Amsterdam: Elsevier Science and Technology 2003:109-20.

12. Poddubnyy D, Haibel H, Listing J, et al. Baseline radiographic damage, elevated acute phase reactants and cigarette smoking status predict radiographic progression in the spine in early axial spondyloarthritis. Arthritis Rheum 2012;64:1388-98.

13. Burd TA, Hughes MS, Anglen JO. Heterotopic ossification prophylaxis with indomethacin increases the risk of long-bone nonunion. J Bone Joint Surg Br 2003;85:700-5.

14. Giannoudis PV, MacDonald DA, Matthews SJ, et al. Nonunion of the femoral diaphysis. The influence of reaming and non-steroidal anti-inflammatory drugs. $J$ Bone Joint Surg Br 2000;82:655-8.

15. Glassman SD, Rose SM, Dimar JR, et al. The effect of postoperative nonsteroidal anti-inflammatory drug administration on spinal fusion. Spine 1998;23:834-8.

16. Bhattacharyya $\mathbf{T}$, Levin $\mathrm{R}$, Vrahas MS, et al. Nonsteroidal antiinflammatory drugs and nonunion of humeral shaft fractures. Arthritis Rheum 2005;53:364-7.

17. Persson PE, Nilsson OS, Berggren AM. Do non-steroidal anti-inflammatory drugs cause endoprosthetic loosening? A 10-year follow-up of a randomized trial on ibuprofen for prevention of heterotopic ossification after hip arthroplasty. Acta Orthop 2005; 76:735-40.

18. Cella JP, Salvati EA, Sculco TP. Indomethacin for the prevention of heterotopic ossification following total hip arthroplasty. Effectiveness, contraindications, and adverse effects. J Arthroplasty 1988;3:229-34.

19. Knelles D, Barthel T, Karrer A, et al. Prevention of heterotopic ossification after total hip replacement. A prospective, randomised study using acetylsalicylic acid, indomethacin and fractional or single-dose irradiation. J Bone Joint Surg Br 1997:79:596-602.

20. Sell S, Willms R, Jany $\mathrm{R}$, et al. The suppression of heterotopic ossifications: radiation versus NSAID therapy-a prospective study. J Arthroplasty 1998;13:854-9.

21. Fransen $\mathbf{M}$, Neal B. Non-steroidal anti-inflammatory drugs for preventing heterotopic bone formation after hip arthroplasty. Cochrane Database Syst Rev 2004;3:CD001160.

22. Romanò CL, Duci $\mathrm{D}$, Romanò $\mathrm{D}$, et al. Celecoxib versus indomethacin in the prevention of heterotopic ossification after total hip arthroplasty. J Arthroplasty 2004;19:14-18.

23. Saudan M, Saudan P, Perneger T, et al. Celecoxib versus ibuprofen in the prevention of heterotopic ossification following total hip replacement: a prospective randomised trial. J Bone Joint Surg Br 2007:89:155-9. 
24. Cohn RM, Della Valle AG, Cornell CN. Heterotopic ossification is less after THA in patients who receive aspirin compared to coumadin. Bull NYU Hosp Jt Dis 2010;68:266-72.

25. Vavken P, Castellani L, Sculco TP. Prophylaxis of heterotopic ossification of the hip: systematic review and meta-analysis. Clin Orthop Relat Res 2009;467:3283-9.

26. Nunley RM, Zhu J, Clohisy JC, et al. Aspirin decreases heterotopic ossification after hip resurfacing. Clin Orthop Relat Res 2011;469:1614-20.

27. McLaren AC. Prophylaxis with indomethacin for heterotopic bone. After open reduction of fractures of the acetabulum. J Bone Joint Surg Am 1990;72:245-7

28. Moore KD, Goss K, Anglen J0. Indomethacin versus radiation therapy for prophylaxis against heterotopic ossification in acetabular fractures: a randomised, prospective study. J Bone Joint Surg Br 1998;80:259-63.

29. Vuolteenaho K, Moilanen T, Moilanen E. Non-steroidal anti-inflammatory drugs, cyclooxygenase-2 and the bone healing process. Basic Clin Pharmacol Toxicol 2008; 102:10-14

30. Blackwell KA, Raisz LG, Pilbeam CC. Prostaglandins in bone: bad cop, good cop? Trends Endocrinol Metab 2010;21:294-301.

31. Krischak GD, Augat P, Blakytny R, et al. The non-steroidal anti-inflammatory drug diclofenac reduces appearance of osteoblasts in bone defect healing in rats. Arch Orthop Trauma Surg 2007;127:453-8.
32. Raisz LG. Prostaglandins and bone: physiology and pathophysiology. Osteoarthr Cartil 1999;7:419-21

33. Zhang $\mathbf{X}$, Schwarz EM, Young DA, et al. Cyclooxygenase-2 regulates mesenchymal cell differentiation into the osteoblast lineage and is critically involved in bone repair. J Clin Invest 2002;109:1405-15.

34. Spiro AS, Beil FT, Baranowsky A, et al. BMP-7-induced ectopic bone formation and fracture healing is impaired by systemic NSAID application in C57BL/6-mice. J Orthop Res 2010;28:785-91.

35. Vane SJ. Differential inhibition of cyclooxygenase isoforms: an explanation of the action of NSAIDs. J Clin Rheumato/ 1998:4(5 Suppl):s3-10.

36. Sieper J, Klopsch T, Richter M, et al. Comparison of two different dosages of celecoxib with diclofenac for the treatment of active ankylosing spondylitis: results of a 12-week randomised, double-blind, controlled study. Ann Rheum Dis 2008;67:323-9.

37. Barkhuizen A, Steinfeld S, Robbins J, et al. Celecoxib is efficacious and well tolerated in treating signs and symptoms of ankylosing spondylitis. J Rheumatol 2006;33:1805-12.

38. Song IH, Poddubnyy DA, Rudwaleit $\mathbf{M}$, et al. Benefits and risks of ankylosing spondylitis treatment with nonsteroidal antiinflammatory drugs. Arthritis Rheum 2008;58:929-38 